\title{
ESTRATEGIAS LINGÜÍSTICAS EN EL INTERROGATORIO JUDICIAL ESPAÑOL: UNA APROXIMACIÓN PRAGMALINGÜÍSTICA
}

\section{LINGUISTIC STRATEGIES ON THE SPANISH COURTROOM QUESTIONING: A PRAGMALINGUISTIC APPROACH}

\author{
Ángel Cervera Rodríguez \\ Universidad Complutense de Madrid \\ cervera1@filol.ucm.es \\ José Torres Álvarez \\ Universidad Complutense de Madrid \\ torresalj@gmail.com
}

Recibido: $15 / 03 / 2016$

Aceptado: 19/07/2016

\begin{abstract}
Resumen
En este artículo se muestra la importancia que tiene la pragmática tanto en la formulación como en el análisis de las preguntas durante los interrogatorios judiciales, pues proporciona al abogado mayores oportunidades para ganar el pleito y al ciudadano una nueva vía para entender mejor el acto judicial. Para ello, se han analizado dos corpus de juicios orales celebrados en Almería y en Barcelona desde el punto de vista fónico, gramatical y pragmático. Asimismo, se ha procedido a la comparación de las fórmulas empleadas -sobre todo, interrogativas y enunciativas de orientación apelativa- en las que se constata el carácter esencial de la pragmática.

PALABRAS CLAVE: lingüística forense, interrogatorio judicial, pragmática, entonación, discurso jurídico español.
\end{abstract}

\begin{abstract}
This article discusses the importance of the pragmatics either in the formulation or the analysis of the questions posed during the courtroom questioning, so it brings the lawyer more opportunities to win the plea and the citizen a new way to a better understanding of the jury act. To this end, we have analyzed two corpus of oral proceedings held in Almeria and Barcelona from the phonic, grammatical and pragmatic point of view. Likewise, one has proceeded to the comparison of the used formulae -especially on the interrogative and declarative of appellative orientation- in which the essential character of the pragmatics is stated.

KEYWORDS: Forensic Linguistics, courtroom questioning, pragmatics, intonation, Spanish courtroom discourse.
\end{abstract}

Para citar este artículo / To cite this article: Cervera Rodríguez, Ángel; Torres Álvarez, José (2016). Estrategias lingüísticas en el interrogatorio judicial español: una aproximación pragmalingüística. ELUA, 30: 61-78. doi:10.14198/ELUA2016.30.03

Enlace / Link: http://dx.doi.org/10.14198/ELUA2016.30.03 


\section{Introducción}

Es evidente que hay una estrecha relación entre la Lingüística y el Derecho, puesto que la lengua, la retórica y la dialéctica constituyen la base del discurso jurídico, tanto en su vertiente oral como en la escrita. Por ello, el objetivo principal de este trabajo consiste en conocer cómo opera esta relación en la situación comunicativa en la que se desarrolla el juicio oral, conocimiento que es necesario tanto para los profesionales del Derecho, porque puede proporcionarles nuevas tácticas procesales, como para el ciudadano lego en esta materia. De este modo, ambos podrán comprender que el hecho de ganar o perder un pleito no solo se basa en las pruebas aportadas por los abogados en la Sala, sino también en la utilización estratégica de una serie de procedimientos y recursos lingüísticos que son característicos de la interacción judicial.

Pese a que se trata de un tema de investigación esencial que interesa a muchos analistas, todavía son escasas las investigaciones centradas en corpus orales reales, debido a las dificultades existentes para recopilar la información y elaborar el material de estudio. Son varias las causas que motivan esta situación. La primera de ellas es de carácter recopilatorio y obedece a la limitación que la legislación impone a los investigadores interesados en acceder a la documentación pertinente para la elaboración de un corpus que permita analizar comunicativamente los procesos judiciales. Así, la Ley Orgánica 15/1999, de 13 de diciembre, de Protección de Datos de Carácter Personal ${ }^{1}$, dificulta en gran medida esta tarea, pues protege la cesión de aquellos datos que permiten la identificación de una persona, como el nombre y los apellidos, la imagen o la grabación de su voz, etc., elementos cuya presencia en el proceso judicial es indiscutible. La segunda causa está relacionada con las reticencias que tanto lingüistas como juristas muestran en los trabajos pertenecientes a la lingüística forense, disciplina intrínsecamente marcada por el carácter interdisciplinar. A ello se refiere Martín del Burgo (2000: 6), al señalar que los juristas son reticentes a seguir las recomendaciones de estilo y de corrección propuestas por los lingüistas en estos términos:

[...] absorbidos por el estudio de lo que consideran materia privativa suya, [los juristas] temen "perder el tiempo" con algo que consideran sabido en su elementalidad y generalidad. Los lingüistas no se consideran obligados a estudiar los temas "legales". En consecuencia, el lenguaje del derecho queda en tierra de nadie.

Por su parte, Taranilla (2012: 32) critica abiertamente la reticencia de muchos lingüistas a analizar los aspectos comunicativos de los llamados lenguajes de especialidad, escudándose en la concepción errónea de que "el estudio de lenguas de especialidad es, en el fondo, una lingüística de segunda”, actitud que en nada ayuda a la publicación de nuevos títulos españoles relacionados con la lingüística forense.

1 Real Decreto 1720/2007 de 21 de diciembre, por el que se aprueba el Reglamento de desarrollo de la Ley Orgánica 15/1999, de 13 de diciembre, de Protección de Datos de Carácter Personal. Se complementa con la Ley 34/2002, de 11 de julio, de Servicios de la sociedad de la información y de comercio electrónico. Estas requieren de desarrollo reglamentario con la peculiaridad de que ambas normas se ordenan a la tutela no solo de los derechos de las personas físicas, sino también de las jurídicas. 
La tercera causa la apunta Cortés (1992: 11), al afirmar que "el comportamiento verbal revela muy frecuentemente nuestra condición social", idea que ha provocado cierta hegemonía en el ámbito hispánico por indagar en corpus escritos, frente a la temprana acogida que el estudio de los corpus orales ha tenido en los países anglosajones.

Así pues, para alcanzar el objetivo planteado, se presenta una aproximación al interrogatorio judicial y, a su vez, se analizan los interrogatorios judiciales de los corpus propuestos aplicando una metodología basada en un análisis lingüístico-pragmático. Asimismo se establecen las comparaciones pertinentes mediante una selección de ejemplos, de los que se deduce la semejanza en los procedimientos de formulación mostrada por los interrogadores de ambos corpus.

\section{Corpus y metodología}

Esta investigación se basa en el análisis de dos corpus elaborados a partir de juicios orales españoles completos. El primero está formado por quince juicios de importancia menor cuya temática se centra en robo, robo con intimidación, delito de lesiones y amenazas, denuncia falsa, delito contra el deber de cumplir la prestación social sustitutoria, agresión, apropiación indebida y malos tratos, recogidos en su gran mayoría en Ridao (2010) y seguidos por el Juzgado de lo Penal número 1 de Almería capital entre los años 2000 y 2002. El segundo de ellos está constituido por diez casos judiciales resueltos por los juzgados penales de Barcelona entre febrero de 2009 y julio de 2010 y recogidos por Taranilla (2011a y 2012) ${ }^{2}$. La dilación temporal que media entre los procesos judiciales no responde a una casualidad, sino que se justifica por el hecho de que en el primer corpus se pretende "preservar la intimidad de los participantes", según Ridao (2010: 27), mientras que el segundo responde a una cuestión estrictamente procesal, pues refleja el tiempo que media entre la apertura y celebración del juicio oral y el dictamen de la sentencia. Este segundo corpus también contiene casos de importancia menor, es decir, está integrado por algunos delitos, como el de robo con violencia al que se une una falta de lesiones, el de quebrantamiento de condena, el de lesiones, el de simulación de delito, el de robo con fuerza en las cosas, el de amenazas en el ámbito familiar junto con una falta de injurias, el que atenta contra la seguridad vial, el de tenencia ilícita de armas, el que atenta contra la propiedad intelectual y el de robo con violencia.

En cuanto a la duración, los juicios que integran el primer corpus suman tres horas, diecisiete minutos y nueve segundos. En cambio, la duración de los procesos judiciales del segundo es considerablemente mayor, ya que los procesos suman un total de cinco horas, cincuenta y nueve minutos y diecinueve segundos.

Otro punto de conexión entre ambos corpus es el método de transcripción empleado. Aunque en los dos se anonimizan todas las referencias que permiten identificar a los intervinientes del proceso, se preserva la fidelidad al discurso original mediante la transcripción de los aspectos vocálicos, prosódicos y gestuales, así como de los errores normativos y gramaticales que tienen lugar durante los distintos procesos, ambos se basan en el método de transcripción del grupo Val.Es.Co (Briz 1998) pero complementándolo con una serie de

2 La publicación que incluye el corpus se titula "La justicia narrante: un estudio sobre el discurso de los hechos en el proceso penal". Véase bibliografía para más información. 
signos que permiten analizar tanto los actos premeditados como los actos no verbales. Estas convenciones de transcripción complementarias se reproducen en las siguientes tablas:

$+($ ) + Fragmentos del discurso en los que se emplea un ritmo de habla muy acelerado.

-( )- Fragmentos del discurso en los que se emplea un ritmo de habla muy pensado.

\{ \} Información confidencial. Por ejemplo, nombres y apellidos, o nombres de calles, pueblos o ciudades, números identificativos como el Documento Nacional de Identidad, entre otros.

Tabla 1. Convenciones de transcripción complementarias del Corpus I (Ridao 2010: 28).

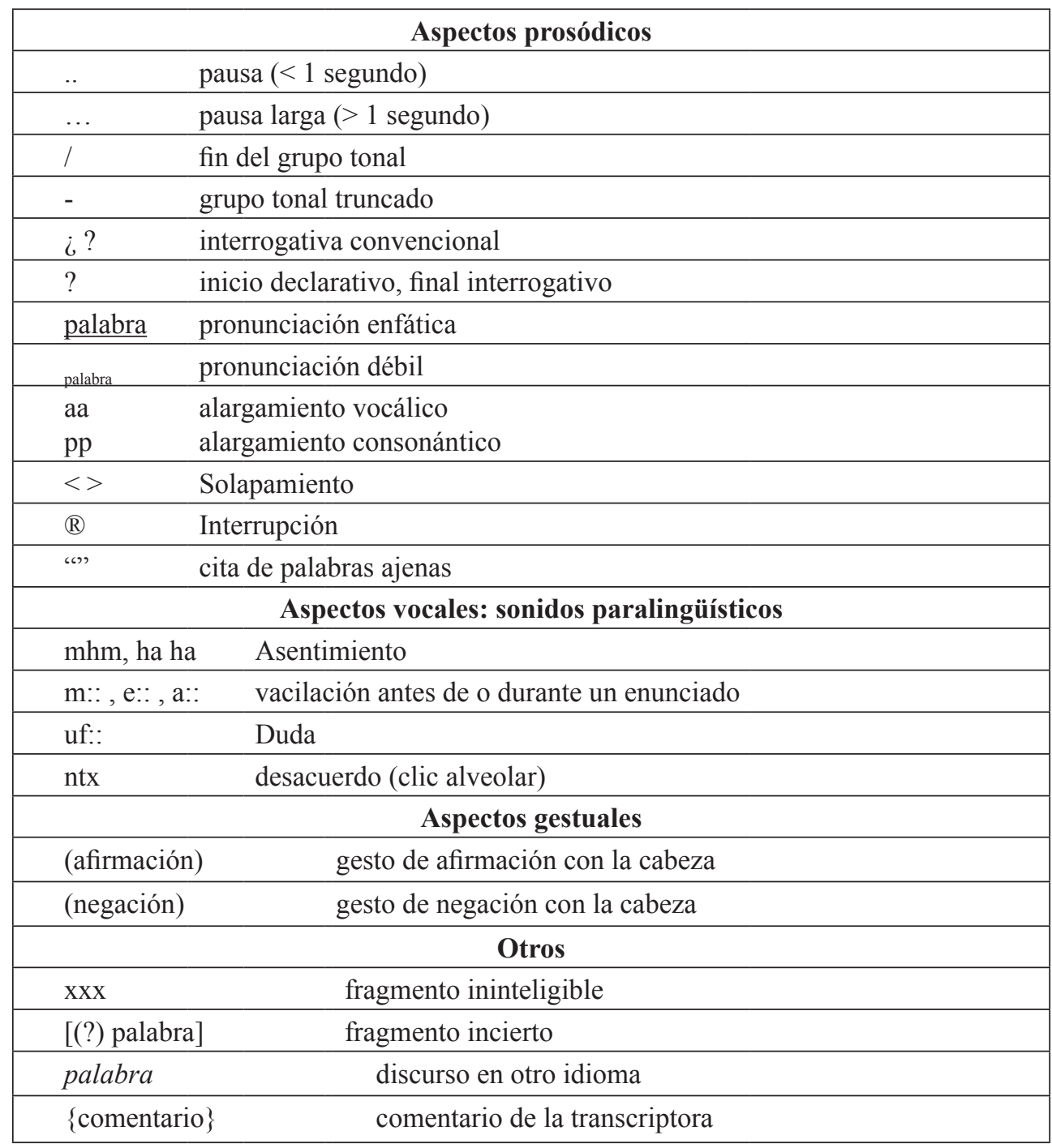




\begin{tabular}{|ll|}
\hline & Elementos de la situación comunicativa \\
\hline$(\mathrm{J})$ & Juez o jueza \\
\hline$(\mathrm{MF})$ & Ministerio fiscal \\
\hline$(\mathrm{D})$ & Defensor \\
\hline$(\mathrm{A}),(\mathrm{O})$ & Acusado \\
\hline$(\mathrm{M}),(\mathrm{M} 1),(\mathrm{R})$ & Testigo \\
\hline
\end{tabular}

Tabla 2. Convenciones de transcripción actualizadas del Corpus II (Taranilla 2012: 13).

En total, se han analizado 2197 intervenciones del juez, del fiscal o del letrado de la defensa con miras a extraer información del testigo interrogado o del propio acusado. Del número total de intervenciones, 995 pertenecen al corpus de Almería y 1202 al corpus de Barcelona. Esta diferencia se debe a que en el corpus de Barcelona hay una mayor participación de la figura del juez en cuanto a que los abogados plantean cuestiones previas al inicio del proceso, lo que lleva a establecer una negociación dialéctica. Asimismo, a diferencia de lo que ocurre en el corpus de Almería, las constantes intervenciones del juez se encaminan a conocer con mayor detalle el fondo del asunto que se va a juzgar y a mantener el orden requerido en el proceso judicial dentro de la Sala.

\section{Aproximación al interrogatorio judicial español}

\subsection{El interrogatorio en el acto judicial}

Uno de los puntos esenciales del acto judicial viene dado por el interrogatorio, definido por el DRAE (2014) en su primera acepción como "Serie de preguntas, comúnmente formuladas por escrito", en la segunda como "Papel o documento que contiene una serie de preguntas" y en la tercera acepción como "Acto de dirigir una serie de preguntas a quien las ha de contestar". Para Ridao (2008b: 805), "es un acto comunicativo de carácter diádico en el que intervienen dos partes, una de ellas tiene la misión de extraer información y la segunda es la que aporta tales datos, teniendo en cuenta las relaciones de poder existentes en estos contextos". Según Taranilla (2011b: 107), responde a una interacción ritualizada de preguntas y respuestas, de manera semejante a la entrevista médico-paciente o al examen oral, en las que un juez, un fiscal y los abogados que ejercen la defensa y, en su caso, la acusación particular, formulan una serie de preguntas a una o a varias personas acusadas o relacionadas con actuaciones ilegales. De cualquier forma, se utiliza habitualmente el término "interrogatorio" para referirse al mecanismo de formular preguntas y respuestas sobre uno o varios asuntos. Tomando como base la teoría pragmadialéctica de la argumentación, Van Eemeren y Grootendrost (2004) consideran que el interrogatorio judicial ${ }^{3}$ es el proceso interactivo que se desencadena entre dos interlocutores que tienen roles y posiciones diferentes: uno que pregunta para obtener o comprobar informaciones, datos o pruebas (el abogado de la defen-

3 Hay que distinguir entre "el interrogatorio establecido a puerta cerrada", que garantiza la eficacia de la interrogación y se preserva como secreto del sumario, y el "careo", considerado como una diligencia utilizada para enfrentar a procesados o testigos ante el órgano judicial con el fin de aclarar las contradicciones observadas en sus declaraciones anteriores. 
sa, el de la acusación particular, el fiscal y el juez), y otro que responde de acuerdo con las preguntas formuladas en relación con los hechos juzgados (el acusado, el testigo y el perito).

Normalmente el interrogatorio de las partes se produce oralmente en presencia del Tribunal en la sede del órgano judicial encargado de la resolución del litigio, excepto cuando concurren situaciones especiales, como la enfermedad, que se realiza en el domicilio o residencia de la parte interrogada. En esta línea, el artículo 315 de la Ley de Enjuiciamiento Civil permite que la Administración Pública pueda contestar al interrogatorio por escrito cuando está inmersa en un proceso civil. Ahora bien, con independencia de que pueda haber excepciones, el Tribunal cita a las partes para su interrogatorio en el juicio oral o vista, que han de estar representadas por un procurador y asistidas de uno o varios letrados.

De acuerdo con los interrogatorios analizados, la forma gramatical más habitual del interrogatorio es la construcción interrogativa a modo de pregunta. Así el interrogatorio forma parte de la teoría de los actos de habla, desarrollada por Austin (1962) y Searle (1980), para quienes los enunciados no solo sirven para constatar o afirmar, sino para realizar acciones lingüísticas diversas en contexto y, por supuesto, para interactuar. En esta línea, la pregunta puede considerarse como un procedimiento fónico-sintáctico a través de la cual el locutor (o interrogador) espera recibir información de la respuesta del alocutor (o interrogado). Ahora bien, aunque el interrogatorio tiene por objeto principal descubrir o dilucidar la verdad de los hechos en el proceso judicial, con frecuencia se recurre a preguntas-trampa que tratan de desconcertar y hacer caer en algo inesperado a la parte contraria con la intención de desvirtuar la verdad de los hechos.

\subsection{La investigación del interrogatorio judicial en el ámbito español}

Es evidente que en los juicios orales el interrogatorio es fundamental; sin embargo, las publicaciones en español sobre aspectos lingüístico-comunicativos aplicados al discurso oral del proceso judicial todavía son escasas. Así lo manifiesta Bernal (2009: 16-17) al indicar que existen muchos aspectos relacionados con la interacción judicial que deben analizarse. Asimismo, Taranilla (2011a: 41-42) propone una clasificación de algunos de los enfoques lingüísticos que se han aplicado al género judicial y concluye que las publicaciones relacionadas con aspectos lingüísticos y pragmático-discursivos del proceso judicial español son novedosos en la investigación hispánica. Aun así, ya existen algunas publicaciones de interés para el investigador sobre el estudio lingüístico-pragmático de actos judiciales, como las de Segura (1998), Ridao (2008a), Bernal (2011) o Briz (2011), etc. y ponencias en congresos y jornadas, como las de Catalá y Jordan (2014) o Torres (2015). Esto demuestra el indiscutible interés por conocer cada vez más y mejor los componentes lingüísticos y las estrategias lingüístico-discursivas que se utilizan en el discurso jurídico oral.

Por lo demás, contrasta el escaso repertorio bibliográfico en español sobre los procedimientos lingüístico-pragmáticos del proceso judicial con la abundante bibliografía existente en inglés. Esta situación tan dispar puede deberse a la facilidad que tienen los investigadores del discurso jurídico para obtener un corpus de referencia. De ello dan cuenta los estudios de Dunstan (1980), que analiza cuál es el valor perlocutivo del interrogatorio judicial, o los de Harris (1984), Philips (1984), Woodbury (1984), Drew (1992) o Heritage (2002), entre otros, que describen cuál es la función pragmática que cumplen las preguntas durante el interrogatorio judicial. Por su parte, Aldridge y Luchjenbroers (2007) ponen de manifiesto que el uso de un determinado léxico durante el interrogatorio condiciona la percepción del juez sobre los sujetos involucrados en el proceso judicial. 
De cualquier forma, muchos de estos estudios constituyen una fuente de referencia a la que conviene recurrir para profundizar en el análisis de los procedimientos lingüísticoforenses españoles, teniendo en cuenta que en el ámbito hispano no se empiezan a publicar regularmente investigaciones centradas en las preguntas del interrogatorio judicial hasta finales del s. XX. Conviene, por ello, referirse a Segura (1998: 81-115), cuyo trabajo supone uno de los primeros intentos de ofrecer una taxonomía básica de las distintas preguntas utilizadas en los interrogatorios judiciales. Asimismo, Ridao (2008a, 2010) nos da a conocer la frecuencia de las distintas intervenciones con valor interrogativo de quince juicios resueltos en los Juzgados de lo Penal de Almería capital entre los años 2000 y 2002. Por su parte, Taranilla (2011a: 318-337) establece una clasificación sin ánimo de exhaustividad de algunas de las preguntas que forman el corpus del presente estudio pero sin llegar a analizarlas. Y, aunque se aborda de forma mucho más breve que en las publicaciones de las investigadoras anteriores, García Ramírez y otros (2012) explican desde una perspectiva comunicativa cómo se utilizan las preguntas abiertas, las cerradas, las capciosas, las sugestivas y las impertinentes en el interrogatorio judicial oral. A pesar de todo, no son demasiados los trabajos centrados específicamente en el análisis de las preguntas formuladas en juicios orales, por lo que se precisan estudios que contribuyan a conocer mejor los procedimientos lingüísticopragmáticos que operan en la interacción comunicativa del acto judicial.

\section{Análisis del corpus}

El conocimiento de los procedimientos lingüístico-pragmáticos es imprescindible para el ejercicio de profesionales del derecho en general y de los abogados en particular. Realmente los abogados precisan de un conocimiento exhaustivo y profundo de la lengua para poder usarla en cada uno de los actos jurídicos no solo con precisión y coherencia, sino también con la adecuación requerida para la orientación pragmática deseada tanto en la modalidad oral como en la escrita. Por esta razón, es necesario que se promuevan investigaciones de carácter lingüístico sobre el discurso jurídico que contribuyan a la mejora de la preparación de los cuestionarios de los actos judiciales orales. En este sentido, señala la Nueva Gramática de la Lengua Española (2009: I, XLVII), en adelante NGLE, que hay que instar a que los abogados "ejerciten la reflexión sobre su propia lengua presentándoles los instrumentos con los que esa reflexión se lleva a cabo en ámbitos más profesionales", esto es, proporcionar a los abogados las herramientas lingüístico-discursivas necesarias para que sus interrogatorios sean más eficaces y sus argumentaciones más consistentes. Para lograr todo esto, los abogados han de aprender a manejar con fluidez, desde los primeros cursos académicos, dos estrategias básicas interrelacionadas: la formalización de preguntas con criterios gramaticales apropiados y la utilización de la entonación adecuada al sentido semántico-pragmático requerido por el contexto en el interrogatorio de que se trate.

\subsection{La entonación en el interrogatorio judicial}

En el ejercicio de su profesión el abogado cuenta con una amplia variedad de procedimientos sintácticos y estrategias discursivas de orientación pragmática para preparar la formulación de preguntas del modo más adecuado y efectivo en cada uno de los interrogatorios previstos. Por ello, conviene conocer las funciones que caracterizan los tipos de entonación y, a su vez, 
reconocer los modelos de entonación asociados a la modalidad oracional, donde concurren aspectos sintácticos, semánticos y pragmáticos, como se recoge en trabajos de referencia como los de Navarro Tomás (1974), Alarcos (1994), Quilis (1997), Escandell (1999), J. Manuel Sosa (1999), Hidalgo Navarro (2006), Gil Fernández (2014) y la NGLE (2009), entre otros. Todos estos trabajos coinciden en que la entonación ${ }^{4}$ realiza dos funciones básicas: una lingüística y otra expresiva. Estas dos funciones están presentes en el discurso jurídico oral con una amplia variedad tonal por el carácter interactivo del interrogatorio judicial y ambas contribuyen a la identificación del valor pragmático con que se proyectan las preguntas.

\subsubsection{La función pragmático-lingüistica de la entonación}

\subsubsection{Función distintiva o significativa}

La función pragmático-lingüística distintiva o significativa permite diferenciar, por ejemplo, una modalidad oracional declarativa (1a) de otra interrogativa (1b):

(1) a) 30- Fiscal: y fue] a a partir de ese momento cuando de decide usted sustraer [el vehículo $\downarrow 31$ - Acusado 2: sí]

(Caso judicial $N^{0} 5$ - Corpus de Almería)

b) D e:: / ¿usted tiene en su casa / había tenido siempre Canalplus / con sus padres? / $\uparrow$ PR sí /

(Caso judicial $\mathrm{N}^{\circ} 9$ - Corpus de Barcelona)

Como se ve, en (1a) el interrogador utiliza una entonación descendente al final de su intervención porque da por cierto los hechos, de ahí que la función del interrogado deba confirmar o refutar esta creencia. En cambio, en (1b) el interrogador recurre a una entonación interrogativa para dilucidar la duda que se plantea, por lo que espera del interrogado únicamente una respuesta absoluta ("sí/no").

\subsubsection{La función delimitadora significativa}

La función pragmático-lingüística delimitadora significativa permite distinguir las subordinadas adjetivas explicativas de la especificativas, al igual que el estilo directo del indirecto, tal y como sucede en el siguiente ejemplo:

(2) $\mathrm{P}(\ldots)$ entendemos que / $\downarrow$ a pesar de que no ha contestado a las preguntas de este letrado / porque se ha acogido a su derecho constitucional a no declarar / cosa que nos parece / por otro lado / ... correcta $\uparrow$ / ha quedado probado que el acusado era administrador de thelastkeys...

(Caso judicial $\mathrm{N}^{\circ} 9$ - Corpus de Barcelona)

4 Prosódicamente, la entonación es la línea melódica constituida por una sucesión de tonos en la cadena hablada -palabra y oración, cuando se actualizan como enunciados- que contribuye al significado semántico-pragmático. 
Como se observa, la oración subordinada adjetiva puede eliminarse sin que ello afecte a la comprensión de la secuencia. El hecho de que el abogado de la acusación particular la emplee responde a una finalidad pragmática muy concreta: criticar la actitud del acusado al negarse a cooperar con la justicia y no responder a las preguntas de esta parte.

\subsubsection{La función delimitadora no significativa}

La función pragmático-lingüística delimitadora no significativa de la entonación sirve para interpretar los enunciados con enumeraciones completas e incompletas, las coordinadas, las subordinadas y los componentes parentéticos, como en

(3) 47- Acusado: esa mujer] mire eeeh a mediados de enero se mandaron circulares a todos los clientes // a través de teléfono $\uparrow$ e-mail $\uparrow$ y correo ordinario $/ \downarrow$ avisando del cierre // $\downarrow$

(Caso judicial No 10 - Corpus de Almería)

En este caso, el acusado enumera todos los canales de contacto que se utilizaron para contactar con los clientes de la tienda de informática ("a través de teléfono $\uparrow$ e-mail $\uparrow$ y correo ordinario / $\downarrow$ ") con la intención de convencer a la juez de que utilizó todos los medios a su alcance para avisar del cierre definitivo del establecimiento.

\subsubsection{La función expresiva}

Además de las funciones lingüísticas, la entonación desempeña una función expresiva, que restringe la respuesta de los sujetos interrogados. Se manifiesta a través de la variabilidad de la entonación dada por las preguntas pronominales que están encabezadas por pronombres o partículas de carácter interrogativo -qué, quién, cuál, dónde, cómo, por qué, de qué modo, etc., como sucede en:

(4) a) J [entonces / ¿quién] se estaba pegando? /

(Caso judicial $\mathrm{N}^{\mathrm{o}} 3$ - Corpus de Barcelona)

b) D pues / con la venia / señoría / ¿usted recuerda lo que ocurrió / el día 7 de marzo de $2006 ? / \downarrow$ por los hechos por los que usted ha sido condenado / por un juzgado dee / de menores $/ / \uparrow$

M sí /

(Caso judicial $N^{\mathrm{o}} 3$ - Corpus de Barcelona)

c) MF usted se- / es amigo $\downarrow /$ ¿no? $\uparrow /$ dee / de Ernesto $/ \downarrow$

(Caso judicial $\mathrm{N}^{\mathrm{o}} 1$ - Corpus de Barcelona)

Se comprueba en (4a) que se formula una pregunta parcial con tonema descendente que lleva implícito el sentido de duda, aunque pueda prever lo que va a responder el interrogado. En (4b) el enunciado responde a una pregunta total que conlleva un final ascendente y una respuesta totalizadora "Sí", aunque pueda explicitarla. Y en (4c) el enunciado se completa 
con un indicador interrogativo final (o apéndice interrogativo) para producir el sentido corroborativo que desea con tonema final ascendente o rama tensiva con anticadencia (4c), donde se ve que hay una inclinación mayor hacia la afirmación que hacia la pregunta.

\subsection{La formulación de preguntas en el interrogatorio judicial}

Las funciones de la entonación están asociadas estrechamente a la voluntad del abogado por probar la veracidad de su versión de los hechos y por desvirtuar la historia presentada por la parte contraria. Sin embargo, también debe tenerse en cuenta que la formulación de un tipo u otro de pregunta servirá para inducir al sujeto interrogado a que responda a la cuestión planteada con mayor o menor amplitud.

La NGLE (2011: III, 466-475) distingue dos tipos de estructuras interrogativas: a) Total, que puede ser polar, si la respuesta es "sí/no", y alternativa, si se puede elegir entre dos o más opciones; y b) Parcial o pronominal, caracterizada por iniciarla un pronombre o adverbio interrogativo. De cualquier forma, los enunciados interrogativos en español se caracterizan por su carácter abierto e incompleto, puesto que los formula un locutor para que un alocutor los complete en la respuesta que se le pide. Pero es evidente que la función pragmática de la interrogación no siempre responde a los esquemas básicos neutros basados en demandar alguna información que desconoce o duda de ella, sino que más bien estos modelos de interrogación pueden ser "no neutros" al utilizarse con otra intencionalidad, como la de orden, el ruego, la expresión de sorpresa, el planteamiento de hipótesis, la confirmación de hipótesis, la suposición, la duda, la pregunta aseverativa, la apelativa, la exclamativa, la reiterativa, la enfática, la alternativa, la encadenada, la disyuntiva, la restrictiva, la inducida, etc., e incluso, se puede hablar de preguntas contrastivas, impositivas, pertinentes, sugerentes, insidiosas, impertinentes, capciosas, sutiles, disparatadas, etc. Puede decirse que los enunciados interrogativos constituyen esquemas que presentan un cierto grado de formalización sintáctica en cuanto que, por ejemplo, el sujeto suele ir pospuesto al verbo, aunque en el Caribe aparece antepuesto. Sin embargo, por razones pragmáticas los enunciados interrogativos pueden variar la colocación de los elementos cuando el interrogador trata de focalizar algún componente anteponiéndolo a la pregunta. Así puede verse en:

(5) 37- Fiscal: ¿eso dice usted que lo hizo en presencia de sus hijos? $\S$

(Caso judicial No 11 - Corpus de Almería)

Como se puede comprobar en (5), el fiscal antepone el demostrativo "eso" con valor deíctivo para focalizar la atención sobre el acto que realizó el acusado en presencia de sus hijos (zarandear a la acusada contra una pared).

De todos modos, para que el interrogatorio sea exitoso un profesional del derecho debe saber formular preguntas con propiedad sintáctica y melódica, con pertinencia semántica y con eficacia pragmática en el acto judicial oral. Nuestro interés se centra, por ello, en señalar el tipo de preguntas fundamentales que suelen formularse durante los interrogatorios que componen los juicios orales del corpus. Nos estamos refiriendo a las preguntas confirmativas u orientadas, a las divergentes, a las alternativas, a las tradicionales y a las pragmáticas, como las denomina Ridao (2008b: 806), pero también a las preguntas híbridas, a las preguntas-trampa y a los apéndices confirmativos. 


\subsubsection{Las preguntas confirmativas $u$ orientadas}

Las preguntas confirmativas u orientadas permiten al abogado buscar el acuerdo con el interlocutor, tal y como sucede en (6), donde el fiscal pretende que el demandante confirme que no existe ninguna duda en relación con las afirmaciones que ha ido realizando durante todo el interrogatorio:

(6) MF ¿no tiene usted / ninguna duda? /

G no / ..

(Caso judicial $\mathrm{N}^{\mathrm{o}} 1$ - Corpus de Barcelona)

Y la misma finalidad se persigue en los siguientes ejemplos, donde el juez pretende que el alocutor proporcione una respuesta clara sobre el hecho que se pregunta:

(7) a) J le advierto a usted / que el falso testimonio en causa judiciaal / puede conllevar penas de prisión / ¿se xxx ratifica usted en el atestado? /

M1 sí /

(Caso judicial № 2 - Corpus de Barcelona)

b) 1- Juez: juicio \{número del juicio\} del año dos mil uno // por delito de robo contra \{nombre y primer apellido de la acusada\} y nnombre y primer apellido del acusado\} $/$ ¿se consideran ustedes CULPABLES [del?

2- Acusado: no]

En (7a), después de informar al testigo de las posibles consecuencias de mentir en un proceso penal, el juez pretende que el agente de policía confirme si se ratifica o no en el atestado. Y en (7b) el juez desea conocer si el acusado se considera culpable del delito que se le acusa. Los aspectos fónico-semánticos de ambas construcciones son los elementos que permiten a los interlocutores entender que ambas formulaciones son una petición de respuesta, pues se pronuncian mediante una línea melódica inequívocamente interrogativa y en su seno incluyen léxico interrelacionado ("ratifica" y "atestado", en el primer ejemplo; "consideran" y "CULPABLES", en el segundo).

(Caso judicial $N^{o} 1$ - Corpus de Almería)

\subsubsection{Las preguntas divergentes}

Las preguntas divergentes permiten que los sujetos interrogados divaguen en su respuesta, por lo que no existe una respuesta única e inequívoca. Por ejemplo, en (8) la pregunta que el fiscal formula al perito requiere de una respuesta amplia que puede estar formada por varias explicaciones, complementarias o suplementarias:

(9) 40- Fiscal: o(¡hola!)o // con la venia señoría eeeh don \{nombre del forense \} usted conocióóó a \{nombre y apellidos del acusado\} en aquella fecha y le le diagnosticó un episodio depresivo grave / eh ¿puede usted concretar exactamente si ese episodio depresivo grave 
/ eeeh tal y como usted hizo esa exploración y ese estudio deeel del diagnóstico de esa persona / eh anulabaaa sus facultades o de alguna manera eeeh quedaban afectadas por esa depresión? §

(Caso judicial No 4 - Corpus de Almería)

\subsubsection{Las preguntas alternativas}

Las preguntas alternativas orientan la respuesta del interrogado, pues contienen los términos sobre los que este debe pronunciarse, como sucede en

(4) J no / señora / señora / señora Gómez / usted no decide las preguntas que contesta / o las que no / se lo digo yo / ¿usted conocía al acusado / porque mantuvo una relación con su hermana? / ¿sí o no? /

(Caso judicial No 10 - Corpus de Barcelona)

donde la juez indica a la señora Gómez que debe responder si es verdad o no (“¿sí o no?/”) que conocía al acusado porque mantuvo una relación sentimental con su hermana. En el caso de que la respuesta fuera negativa, el juez debería buscar un nexo que uniera al acusado con la interrogada; en cambio, si la respuesta fuera afirmativa, la denuncia carecería de fundamento, pues se entiende que, antes de que se presentara la denuncia, la señora Gómez mantenía una relación afectiva con el que fuera su cuñado.

\subsubsection{Las preguntas tradicionales}

Las preguntas tradicionales pretenden que el interrogado se pronuncie acerca del hecho sobre el que se pregunta de dos maneras distintas. En la primera opción, el interrogador emplea una pregunta absoluta, en terminología de Navarro Tomás (1974: 101), llamada también pregunta total, según la denominación de Escandell (1999: 3932), para conseguir que el interrogado proporcione información sobre los hechos pero restringiendo su respuesta, ya que normalmente se intenta que la incógnita de la predicación se despeje mediante sí o no. Así lo podemos observar en:

(5) a) MF dice usted / que iba- / que iba borracho / el día ese dee /

DDO sí / había estao trabajando / había estao casi todo el díaa / por ahi / bebiendo / $\mathrm{xxx} /$

(Caso judicial $\mathrm{N}^{\circ} 4$ - Corpus de Barcelona)

b) 81- Letrado: = ¿está usted bajo tratamiento? $\S$

82- Acusada: sí §

(Caso judicial $N^{o} 1$ - Corpus de Almería)

En (5a) la explicación complementaria que sigue al adverbio positivo que encabeza la intervención de DDO no es más que un recurso del hablante para intentar justificar su embriaguez (“...había estao trabajando / había estao casi todo el díaa / por ahi / bebiendo"), 
mitigando de este modo el perjuicio a su imagen pública. Y la misma finalidad se persigue en (5b), donde el letrado pretende mitigar el daño sobre el polo positivo de la imagen social de la acusada, consumidora habitual de estupefacientes, indicando que en la actualidad se encuentra bajo tratamiento médico con la finalidad de controlar su adicción.

Mediante la segunda opción los interrogadores pretenden que el sujeto interrogado proporcione información más detallada sobre la cuestión preguntada, pero restringiendo el alcance de su respuesta al qué, al quién, al cómo, al dónde, al por qué y al cuándo del hecho. Para ello, el interrogador emite una secuencia que se inicia y finaliza con una entonación ascendente, como se ve en:

(6) a) $\quad \mathrm{P}$ ¿por qué no va al público en general? $/ \uparrow$

P2 porque no da ningún tipo de instrucción / de cómo tiene que usarse / la información que expone /

(Caso judicial $N^{o} 9$ - Corpus de Barcelona)

b) 459- Letrado: ¿qué día se cerró la tienda concretamente? // $\uparrow(2,5$ ”)

460- Testigo 3: la tienda se cerróóó /// (1,5") el día dos de febrero si mal no recuerdo / [terminamos de / vamos que yo terminara

(Caso judicial No 10 - Corpus de Almería)

Como se puede comprobar en (6a), el letrado de la acusación particular intenta que el perito de informática aporte y justifique una afirmación realizada en un momento anterior del juicio, mediante la que afirmaba que la página web que mantenía el acusado, donde se revelaban las contraseñas para acceder gratuitamente a una plataforma televisiva de pago, no se dirigía a un público lego en informática. Asimismo en (6b) el letrado pretende que el testigo confirme en qué fecha exacta se cerró una tienda de informática donde se realizó una supuesta reparación de un equipo informático.

Desde una perspectiva pragmática, este tipo de preguntas tiene un gran valor para los letrados, ya que su formulación invalida la posibilidad de que los hechos preguntados vuelvan a ser referidos sin que el juez amoneste al interrogador indicándole que ya se ha respondido a dicha cuestión.

\subsubsection{Las preguntas pragmáticas}

Las preguntas pragmáticas, según Ridao (2008b: 806), se utilizan para solicitar información de forma indirecta, mediante una entonación no interrogativa, sino enunciativa. Es lo que sucede en los siguientes ejemplos:

(7) a) MF usted luego / al cabo del tiempo / acudió a las dependencias judiciales / a los juzgados / C sí /

(Caso judicial No 10 - Corpus de Barcelona)

b) 14- Fiscal: +(él estaba allí / este señor $)+\S$

15- Policía Local 1: sí sí sí §

(Caso judicial $\mathrm{N}^{\mathrm{o}} 7$ - Corpus de Almería) 
En (7a) la fiscal intenta que C confirme su asistencia a los juzgados bastante tiempo después de que ocurrieran los hechos. Pero, frente a lo esperable, la demanda de información no se obtiene mediante una secuencia interrogativa, sino mediante una secuencia enunciativa que el receptor descodifica e interpreta como una petición de información. Y lo mismo ocurre en $(7 b)$, donde el agente de policía infiere que el fiscal le solicita la confirmación de la presencia en el lugar de los hechos de otro participante en el juicio oral.

\subsubsection{Las preguntas híbridas}

Las preguntas híbridas se sitúan a medio camino entre las preguntas tradicionales y las preguntas pragmáticas, pues su formulación contiene una secuencia enunciativa seguida de un apéndice modalizador interrogativo, como se ve en:

(8) a) MF usted a esta persona / no la conoce de nada / ¿no? $/ \uparrow$ O yo no la conozco de naa /

(Caso judicial $\mathrm{N}^{\mathrm{o}} 1$ - Corpus de Barcelona)

b) 10- Fiscal: +(un par de aclaraciones / ustedes sorprendieron a este señor al lado del de la alhóndiga ¿no? / al lado al lado de donde se [había producido)+

11- Policía Local 1: (( )) del almacén

(Caso judicial $\mathrm{N}^{\mathrm{o}} 7$ - Corpus de Almería)

En (8a) el fiscal pretende que el interrogado confirme que no conoce al sujeto al que se está haciendo referencia en el interrogatorio. Para ello, formula una afirmación ("usted a esta persona / no la conoce de nada") de la que pide la confirmación mediante el modalizador “¿no?”. Lo mismo sucede en (8b), pues el fiscal pretende que el agente de policía confirme el lugar en el que se encontraba el sujeto mediante una emisión enunciativa a la que sigue un elemento modalizador interrogativo ("ustedes sorprendieron a este señor al lado del de la alhóndiga ¿no?”). De nuevo, la formulación de este tipo de preguntas requiere que el interlocutor realice un esfuerzo cognitivo importante, pues debe interpretar que se le está solicitando la confirmación de cierta información.

\subsubsection{Las preguntas- trampa}

Mediante la formulación de las preguntas trampa, los abogados pretenden que el sujeto interrogado proporcione información que no está relacionada con los hechos que han originado el inicio del proceso, como sucede en

(9) D ¿es la primera vez que han intentado atracarla? /

$\mathrm{R}$ no / por desgracia / no /

$\mathrm{D}$ en el local donde usted trabaja- / trabajó anteriormente / ¿era / probablemente / una frutería? /

$\mathrm{R}$ yo estaba trabajando antes en una fru[tería] /

(Caso judicial $\mathrm{N}^{\mathrm{o}} 10$ - Corpus de Barcelona) 
la abogada que ejerce la defensa (D) formula una pregunta trampa (" $¿$ era / probablemente / una frutería? /") puesto que la información que se pretende conseguir no está relacionada directamente con los hechos que se enjuician, esto es, el atraco a una panadería donde trabaja $\mathrm{R}$, sino que hace referencia a un momento anterior a la celebración del proceso judicial. Por ello, y debido a que la letrada intenta dejar en evidencia al sujeto que va a responder, el juez -como observador imparcial- percibe la implicación sesgada de esta pregunta y puede llegar a invalidarla por considerar que no es pertinente o que no contribuye al conocimiento real de los hechos e incluso puede recriminar la actitud de la letrada:

(10) $\mathrm{J}$ [pero] / ¿qué tiene que ver [esto con los hechos? / señora letrada /]

(Caso judicial No 10 - Corpus de Barcelona)

Como se observa en (10), el juez no acaba de entender por qué la abogada de la defensa formula la pregunta mostrada en (9), por lo que recrimina esta actuación antes de solicitarle que prosiga con el interrogatorio mediante la formulación de otras preguntas relacionadas con los hechos enjuiciados.

\subsubsection{Los apéndices confirmativos}

Durante los interrogatorios judiciales, los abogados no solo se basan en la formulación de las preguntas que hemos analizado hasta el momento para intentar ganar el pleito, sino que también es habitual formular preguntas mediante el procedimiento gramatical enunciativo seguido de apéndices interrogativos. Por ejemplo:

(11) a) J vamos a ver / dice usted / que después se metió mucha gente / y empezó a pegar / "yo no sé a quién ni cómo" / ¿no? /

M caro /

(Caso judicial $\mathrm{N}^{\mathrm{o}} 1$ - Corpus de Barcelona)

b) 63- Fiscal: iban ustedes solos en el coche cuando los sorprendieron ¿no? $\S$

64- Acusada: o(sí señora)o $\S$

(Caso judicial $\mathrm{N}^{\mathrm{o}} 1$ - Corpus de Almería)

Como se ve, en (11a) la juez utiliza el apéndice interrogativo “¿no?” para que M confirme tanto su versión de los hechos ("después se metió mucha gente / y empezó a pegar") como las palabras que acaba de formular en una intervención anterior; sin embargo, en (11b) la Fiscal utiliza este mismo apéndice interrogativo para que la acusada confirme el hecho de que únicamente ella y su marido fueron sorprendidos por una patrulla cuando circulaban en su coche. 


\section{Conclusión}

En este artículo se ha analizado el interrogatorio judicial español desde una perspectiva lingüístico-pragmática tomando como base las fórmulas interrogativas más representativas de los juicios orales recogidos en los dos corpus propuestos, uno de Almería y otro de Barcelona.

El análisis se ha centrado en la explicación de algunos de los aspectos lingüísticopragmáticos constitutivos de la interrogación, como las funciones y los esquemas de entonación, considerados como modelos representativos de los enunciados del español. Se ha constatado que hay muchas afinidades en la formulación de las preguntas en ambos corpus cuando los abogados tratan de perseguir lo mismo, lo que explica la intertextualidad del discurso judicial. También se ha podido comprobar que los abogados siguen una serie de patrones comunes para condicionar, en mayor o menor medida, la respuesta del interrogado, asegurándose así una mayor ventaja con el fin de ganar el pleito.

A través del tipo de interrogación utilizado en ambos corpus se ha reconocido no solo la modalidad oracional desde una perspectiva prosódica, sino también el significado semántico y el sentido pragmático con que la proyectó el interrogador para obtener la respuesta deseada. Asimismo, se ha mostrado que la planificación con la que actúa el abogado durante el desarrollo del interrogatorio judicial aumenta las posibilidades de lograr éxito en el juicio, ya que puede formular preguntas cerradas, cuyas respuestas se limiten a responder "sí" o "no", y otras más abiertas, que permitan obtener mayor información sobre los hechos encausados mediante explicaciones o relatos explícitos.

Finalmente, cabe señalar que, a pesar de que en ambos corpus se recurre a un tipo semejante de interrogaciones, existen diferencias significativas en la formulación de las preguntas. Así, mientras que en el corpus de Almería predomina el uso de la interrogación pragmática, en el de Barcelona destaca el de la interrogación tradicional. Independientemente de esta diferencia, el propósito de los abogados de ambos corpus es el mismo: defender de la forma más efectiva posible a su cliente, de ahí que planifiquen tanto el modo de formular las preguntas durante el interrogatorio como la frecuencia de uso de las mismas para jugar a su favor al condicionar la respuesta del interrogado.

\section{Referencias bibliográficas}

Alarcos Llorach, Emilio (1994). Gramática de la lengua española. Madrid: Espasa Calpe.

Aldridge, Michelle y Luchjenbroers, June (2007). "Linguistic manipulations of witness testimonies: Framing questions and 'smugging' information? En International Journal of Speech, a ganar Language and the Law, 14, 1, pp. 83-107.

Austin, J. L. (1962). Cómo hacer cosas con palabras. Barcelona: Paidós.

Bernal Linnersand, María (2011). "La oralidad en la situación de juicio. Análisis de los rasgos coloquiales en el juicio del 11-M”. En Lars Fant, Ana María Harvey (eds), El diálogo oral en el mundo hispanohablante: estudios teóricos y aplicados, Madrid, Frankfurt am Main, Iberoamericana, Vervuert Verlag, pp. 123-145.

Briz Gómez, Antonio (1998). El español coloquial en la conversación. Esbozo de pragmalingüistica. Barcelona: Ariel.

Briz Gómez, Antonio (2011). "El juicio oral: un subgénero de lo +formal”. En Lars Fant, Ana María Harvey (eds), El diálogo oral en el mundo hispanohablante: estudios teóricos y aplicados, Madrid: Frankfurt am Main, Iberoamericana, Vervuert Verlag, pp. 105-121. 
Catalá Pérez, Manuela y Jordan Núñez, Keneth (2014). "Murderers also speak. The use of the term 'exactamente' in the case of José Bretón and crime simulation". Comunicación presentada en las III Jornadas (In)formativas de Lingüística Forense, Madrid, Universidad Autónoma de Madrid (24 de octubre de 2014).

Cervera Rodríguez, Ángel y Torres Álvarez, José (2015). “Análisis conversacional del discurso procesal español”, Pragmalingüistica, 23, Universidad de Cádiz, pp. 8-21.

Cortés Rodríguez, Luis (1992). Estudios de español hablado. Aspectos teóricos y sintáctico-cuantitativos, Almería: Instituto de Estudios Almerienses.

Drew, Paul (1992)."Contested evidence in courtroom cross-examination: the case of a trial for rape". En Drew, Paul y Heritage, John (eds.), Talk at work: interaction in institutional settings. Cambridge, Cambridge University Press, pp- 470-520.

Dunstan, Robert (1980). "Contexts of Coercion: Analyzing Properties of Courtroom 'Questions", British Journal of Law and Society, 7, pp. 61-77

Escandell-Vidal, Ma Victoria (1999). "Los enunciados interrogativos. Aspectos semánticos y pragmáticos". En Bosque, Ignacio y Demonte Barreto, Violeta (dirs.), Gramática Descriptiva de la Lengua Española. Madrid, Espasa Calpe, vol III, cap. 61. pp. 3929-3991.

España (1999). Ley Orgánica 15/1999, de 13 de diciembre, de Protección de Datos de Carácter Personal. En Boletín Oficial del Estado, núm. 298, de 14 de enero de 2000.

España (2000). Ley 1/2000, de 7 de enero, de Enjuiciamiento Civil. En Boletín Oficial del Estado, núm. 7, de 8 de enero del 2000.

España (2002). Ley 34/2002, de 11 de julio, de Servicios de la sociedad de la información y de comercio electrónico. En Boletín Oficial del Estado, núm. 166, de 12 de junio de 2002.

España (2008). Real Decreto 1720/2007, de 21 de diciembre, por el que se aprueba el Reglamento de desarrollo de la Ley Orgánica 15/1999, de 13 de diciembre, de Protección de Datos de Carácter Personal. En Boletín Oficial del Estado, núm. 17, de 19 de enero de 2008.

Fant, Lars y Harvey, Ana María (eds) (2011). El diálogo oral en el mundo hispanohablante: estudios teóricos y aplicados. Madrid: Frankfurt am Main, Iberoamericana, Vervuert Verlag

García Ramírez, Julio; Romero Santos, Luis; García González, Florentino (2012). La técnica del interrogatorio. Madrid: Editorial Rache.

Gil Fernández, Ma Juana (2014). Los sonidos del lenguaje. Madrid: Síntesis.

Harris, Sandra (1984). "Questions as a mode of control in magistrates' courts", International Journal of the Sociology of Language, 49, pp. 5-27.

Heritage, John (2002). "The limits of questioning: Negative interrogatives and hostile question content”, Journal of Pragmatics, 34, pp. 1427-1446.

Hidalgo Navarro, Antonio (2006). Aspectos de la entonación española: viejos y nuevos enfoques. Madrid: Arco libros.

Martín del Burgo y Marchán, Ángel (2000). El lenguaje del derecho. Barcelona: Bosch.

McGaughey, Karen J. y Stiles, William B. (1983). "Courtroom interrogation of rape victims: Verbal response mode use by attorneys and witnesses during direct examination versus cross-examination", Journal of Applied Psychology, 13, 1, pp. 78-87.

Navarro Tomás, Tomás (1974. Manual de entonación española. Madrid, Guadarrama.

Philips, Susan (1984). "The social organization of questions and answers in courtroom discourse: a study of changes of plea in an Arizona court", Text, 4, pp. 225-248.

Quilis, Antonio (1997). Principios de fonología y fonética española. Madrid: Arco Libros.

RAE y Asociación de Academias de la Lengua Española (2009-2011). Nueva Gramática de la lengua española. Madrid: Espasa Calpe. Vols. I, II y III.

RAE y Asociación de Academias de la Lengua Española (2014). Diccionario de la Lengua española (DRAE). Madrid: Espasa Calpe.

Ridao Rodrigo, Susana (2008a). Análisis pragmalingüistico de resoluciones de conflicto. Las mediaciones laborales: propuestas de investigación. Almería: Universidad de Almería. 
Ridao Rodrigo, Susana (2008b). "El interrogatorio en los contextos judiciales. Una aproximación pragmalingüística". En Monroy Casas, Rafael y Sánchez Pérez, Aquilino (Coods.), 25 años de lingüistica en España, pp. 805-809: http://dialnet.unirioja.es/servlet/libro?codigo=520017 (5-022016).

Ridao Rodrigo, Susana (2009). "El interrogatorio en los contextos judiciales: análisis del tipo y la frecuencia de las preguntas utilizadas en los juzgados de lo penal de Almería capital", Interlingüistica, 18, pp. 940-950.

Ridao Rodrigo, Susana (2010). El género judicial. Materiales para su estudio lingüístico. Extremadura: Junta de Extremadura, Consejería de Educación, Ciencia y Tecnología, Monográfico número 3.

Segura Oronich, Ángel (1998). El Imputado y el Testigo ante el Juez. Psicología del Interrogatorio. Barcelona: Cedecs.

Searle, John (1980). Actos de habla. Madrid: Cátedra.

Sosa, J. Manuel (1999). La entonación del español. Su estructura fónica, variabilidad y dialectología. Madrid: Cátedra.

Taranilla García, Raquel (2011a): La configuración narrativa en el proceso penal. Un análisis discursivo basado en hechos. Barcelona: Universitat de Barcelona. Tesis doctoral: http://www.tdx.cat/ handle/10803/48717 (10-07-16).

Taranilla García, Raquel (2011b): “Análisis lingüístico de la transcripción del relato de los hechos en el interrogatorio policial”, ELUA, 25, pp. 101-134.

Taranilla García, Raquel (2012). La Justicia Narrante. Un estudio sobre el Discurso de los Hechos en el Proceso Penal. Madrid: Aranzadi.

Torres Álvarez, José (2015). "Poder, solidaridad y (des)cortesía: el papel del juez y el juicio oral". Comunicación presentada en las IV Jornadas de Iniciación a la Investigación, Madrid: Universidad Complutense de Madrid (25 de marzo de 2015).

Van Eemeren, Frans H., y Grootendorst, Bob (2004): A Systematic theory of argumentation: the pragma-dialectial approach. Cambrdige: Cambridge University Press.

Woodbury, Hanni (1984). "The strategic use of questions in court”, Semiotica 48, pp. 197-228. 